\title{
The choice of female or male parent affects some biochemical characteristics of fruit or seed of kiwiberry (Actinidia arguta)
}

\author{
Agnieszka Stasiak • Piotr Latocha $(\mathbb{D} \cdot$ Jerzy Drzewiecki $\cdot$ Ewelina Hallmann • \\ Katarzyna Najman · Hanna Leontowicz - Maria Leontowicz • Barbara Lata
}

Received: 18 June 2018/ Accepted: 11 February 2019/Published online: 18 February 2019

(C) The Author(s) 2019

\begin{abstract}
Kiwiberry (Actinidia arguta) is dioecious species which is now commercially grown in several countries worldwide. A study was conducted to determine the influence of five pollen sources derived from A. arguta (three cultivars), A. arguta var. purpurea 'Rot' and A. chinensis var. deliciosa 'Tomuri' on fruit and seed characteristics for three female A. arguta cultivars. Average fruit weight and biochemical features-fruit total phenolic concentration (TPC), ascorbate (ASC), pigments, total antioxidant activity and seed proteins profile were evaluated. TPC was determined using the Folin-Ciocalteu reagent
\end{abstract}

Electronic supplementary material The online version of this article (https://doi.org/10.1007/s10681-019-2375-8) contains supplementary material, which is available to authorized users.

\footnotetext{
A. Stasiak · P. Latocha $(\bowtie)$

Department of Environmental Protection, Faculty of Horticulture, Biotechnology and Landscape Architecture, Warsaw University of Life Sciences (SGGW), 02-776 Warsaw, Poland

e-mail: piotr_latocha@sggw.pl

J. Drzewiecki

Plant Breeding and Acclimatization Institute, National

Research Institute, 05-870 Radzików, Poland

E. Hallmann · K. Najman

Department of Functional Food, Ecological Food and

Commodities, Faculty of Human Nutrition and

Consumption, Warsaw University of Life Sciences

(SGGW), 02-776 Warsaw, Poland
}

assay. ASC, individual phenolic compounds and pigments composition were analysed using HPLC technique. Seed protein composition was analysed based on SDS-PAGE. Fruit phenolic and dry matter contents were influenced to a large degree by pollen sources while ASC content did not. The type of male and female parents used in the study were found to have a considerable effect on these parameters. The biggest differences in fruit phytocompound contents were found between female parents. The 'Geneva' cultivar showed the highest concentration of the most bioactive compounds tested. Four phenolic acids and five flavonoids were present in the highest concentrations in tested kiwiberry fruit. Actinidia chinensis var. deliciosa 'Tomuri' pollen clearly modified the seed protein spectrum with a 17 and $23 \mathrm{kDa}$ protein. The

\footnotetext{
H. Leontowicz · M. Leontowicz

Department of Physiological Sciences, Faculty of Veterinary Medicine, Warsaw University of Life Sciences (SGGW), 02-776 Warsaw, Poland

B. Łata

Laboratory of Basic Sciences in Horticulture, Faculty of Horticulture, Biotechnology and Landscape Architecture, Warsaw University of Life Sciences (SGGW), 02-776 Warsaw, Poland
} 
obtained results indicate that to achieve desired fruit biochemical characteristics, the pollen source (male vines) should be selected individually for particular female cultivars, especially in the case of polyphenol content. Our findings suggest that not only A. arguta but also A. arguta var. purpurea and A. chinensis var. deliciosa 'Tomuri' males may be suitable as pollinizers for kiwiberry fruit production.

Keywords Metaxenia - Seed protein spectrum . Pigments · Phenolics $\cdot$ Ascorbate $\cdot$ Total antioxidant activity

\section{Introduction}

Xenia is defined as the differential effects of fertilization with various pollen sources on the size, shape, colour or chemical composition of seeds and fruits (Denney 1992). Xenia is the effect of the pollen on the endosperm and embryo development (seed tissues) or the effect of the pollen on fruit tissues and can be used to identify the best male parent to improve fruit yield and quality in mixed cultivar plantings (Olfati et al. 2010). This phenomenon has been found in many popular fruit crops including blueberries (Ehlenfeldt 2003), apples (Militaru et al. 2015), grapes (Sabir 2015), sour cherries (Ansari et al. 2010), and olives (Shemer et al. 2014), as well as in vegetables such as tomatoes (Piotto et al. 2013) and cucumbers (Olfati et al. 2010). These studies tended to focus mainly on the relationships between xenia and physical or basic chemical fruit properties. Xenia effects are also known to occur in certain nut crops such as date palm (Shafique et al. 2011) and hazelnut (Fattahi et al. 2014). The effect of male genotypes on seed quality was described for winter oilseed rape (Hom 2004) and rye hybrids (Grochowski et al. 1995; Grochowski 2003). Seed proteins can be useful genetic markers for obtaining estimates of outcrossing (Ferreira et al. 2000). There is currently very little information about the effect of genetically different pollen sources on fruit biochemical composition. The total soluble solid, sugar, acid, vitamin $\mathrm{C}$ and chlorophyll concentrations were significantly affected by different pollen sources in the litchi cultivar 'Guiwei' (Qiu et al. 2006). An investigation to select the best pollen source for the fig cultivar 'Fied' revealed that pollen sources had a significant influence on the total soluble solids and flavonoids content (Pourghayoumi et al. 2012).

The genus Actinidia Lindl. belongs to the Actinidiaceae family and includes 54 species (Huang 2014). Fruit of the species A. chinensis known as kiwifruit, are the most popular. Since all Actinidia species are dioecious, efficient pollination is essential for fruit set and its final quality. Kiwifruit xenia was recently studied by Qj et al. (2007) and Seal et al. (2013). Qj et al. (2007) found that different pollen affected several kiwifruit traits such as setting rate, final fruit weight, soluble solids concentration, transverse diameter, longitudinal diameter, fruit shape index, flesh firmness as well as fruit shape. Seal et al. (2016) reported that pollination of diploid A. chinensis seedlings with pollen from the hexaploid male $A$. chinensis var. deliciosa reduced fruit set, fresh weight, dry matter concentration, weight and number of seeds and expression of red pigmentation in the fruit compared with pollination with pollen from diploid A. chinensis. In contrast to many other diploid $A$. chinensis genotypes, pollination of the cultivar 'Hort 16A' by males of higher ploidy may be beneficial in terms of fresh fruit weight (Seal et al. 2013). An interesting study of the xenia effect on the chemical composition of A. eriantha fruits was recently made in China (Seyrek et al. 2017). The authors found that vitamin C, flavonoid, carotenoid and chlorophyll concentrations in fruit pollinated with different pollen sources differed significantly.

The fruit of Actinidia arguta often traded as kiwiberry, hardy kiwi or mini kiwi, is grape-sized, with a thin, edible and predominantly green skin, but some red skinned cultivars are also available (Huang 2014). It is a new entry into the produce market with growing worldwide consumer acceptance. Its commercial cultivation has gained strong interest in recent years with production increasing steadily. Available research points to kiwiberries being one of the most nutritionally rich fruits in the world (Latocha et al. 2015; Latocha 2017; Leontowicz et al. 2016a). Additionally, they have significant health-promoting properties (Leontowicz et al. 2016a, b).

As xenia has been described for many different fruit species, there is a high probability that it may also be present in kiwiberries. Our hypothesis is that pollen source may affect fruit and seed biochemical composition, and that these traits may also depend on parent. To our knowledge, no research on the effect of xenia 
on bioactive ingredients and antioxidant activity of kiwiberry fruit (A. arguta) is currently available. Therefore, to test the above hypothesis, the influence of female and male parents on selected physical and biochemical characteristics of A. arguta fruit and seeds obtained from crossing was examined in this study.

\section{Materials and methods}

Fruit and seeds samples and their preparation

Three female A. arguta (Siebold et Zucc.) Planch. ex Miq. cultivars ('Geneva', 'Weiki' and 'Bingo', all tetraploid) and five genetically different pollen sources (A. arguta 'Rubi', 'Nostino' and 'Joker'; A. arguta var. purpurea (Rehder) C.F. Liang ex Q.Q. Chang 'Rot' A. chinensis var. deliciosa (A. Chev.) A. Chev. 'Tomuri'), were used in this experiment. The plants of female cultivars were grown in an orchard in central Poland in the Mazovian Region (N 51 $50^{\prime}$; E $20^{\circ} 49^{\prime}$ ). All plants were 6 years old and in full production, healthy and vigorous. Plants were trained on T-bar supports and maintained according to standard recommendation for this growing system (Strik 2005). In spring, mineral fertilizer was applied based on soil analysis. Soil samples were collected at the beginning to mid of March depending on the weather conditions. Macronutrients were extracted using $0.03 \mathrm{M}$ acetic acid, whereas in case of micronutrients Lindsey solution (mixture of ammonia, edetic acid, calcium acetate and citric acid) was used as an extractor. Afterwards those elements were determined using standard analytical methods. An essential nutrients were kept at an average level according to the recommended range for orchard soils (Komosa 2012). The guide values for $\mathrm{N}, \mathrm{P}, \mathrm{K}, \mathrm{Ca}, \mathrm{Mg}, \mathrm{S}$ (in $\mathrm{mg}$ $100 \mathrm{~g}^{-1}$ dry weight (DW) and $\mathrm{Fe}, \mathrm{Zn}, \mathrm{Mn}, \mathrm{Cu}, \mathrm{B}$ (in $\left.\mathrm{mg} \mathrm{kg}{ }^{-1} \mathrm{DW}\right), \mathrm{pH}_{\mathrm{H} 2 \mathrm{O}}, \mathrm{EC}\left(\mathrm{mS} \mathrm{cm}^{-1}\right)$ were the following: $2.5-5.0 ; 3-6 ; 5-8 ; 25-60 ; 3-6 ; 1-3$ and $75-120 ; 5-25 ; 20-40 ; 1-4 ; 0.5-1.5 ; 5.5-6.5 ;<0.5$, respectively. For each female cultivar three vines having similar vigour were randomly chosen (one vine as biological replicate). For each female cultivar, 15 summer shoots each containing at least 30 flower buds in late spring were marked ( 5 shoots on each of three female plants-one for pollination by each male parent). These shoots were isolated with bags before flowering. At full bloom flowers were hand-pollinated with a small brush and again isolated for a week to avoid random pollination. Three different male $A$. arguta genotypes ('Rubi', 'Nostino' and 'Joker') and one A. arguta var. purpurea 'Rot', all tetraploids, were grown in the experimental field of the Environmental Protection Department, Warsaw University of Life

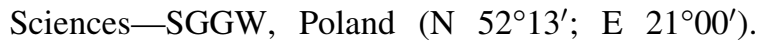
Pollen was collected from closed flowers just before opening. Anthers from each male were cut off into a petri dish, dried at $25^{\circ} \mathrm{C}$ and kept tightly enclosed for 1-3 days in the refrigerator before use. Actinidia chinensis var. deliciosa 'Tomuri' (hexaploid) pollen was imported from Argentina a few months earlier and stored deep frozen $\left(-80{ }^{\circ} \mathrm{C}\right)$ until used. Pollen of all sources was examined before use as described in Stasiak et al. (2017). Pollen viability and was $94.1-100 \%$ and germination ability was $86.4-97.1 \%$.

Fruit was collected at the eating ripeness stage based on fruit firmness (palpably soft fruits) separately for each marked shoot. Fresh fruit weight (FW) and dry matter (DM) were determined for each malefemale combination prior to the fruit freeze-drying process (for each shoot all fruits were counted and weighed; DM was measured on 3 replicates (four fruit for each replicate), based on the method described by Hallmann and Rembialkowska (2012). Average fruit weight was measured over two consecutive growing seasons (2015-2016). All other analyses were performed on fruit harvested in 2015. Both seasons differed significantly with respect to the weather conditions. The year 2015 was very dry whereas 2016 was very humid with a higher precipitation than the long term average (Supplementary material 1).

Samples of A. arguta fruit (15 fruits per shoot) were frozen at $-80^{\circ} \mathrm{C}$ and then freeze-dried before analysis. Small pieces of fruits were placed into plastic boxes $(250 \mathrm{~mL})$ and then freeze-dried using a LabconCo 2.5 freeze drying machine (Labconco Corp., Kansas City, MO, USA). The freeze drying parameters included: temperature $-40{ }^{\circ} \mathrm{C}$, pressure $0.080 \mathrm{mBar}$ and freeze drying time of $72 \mathrm{~h}$. Samples were then milled into a fine powder with a laboratory mill Grindomix Retch GM 200 (Retsch GmbH, Germany). Powdered fruit samples were kept in 20-mL plastic tubes in a freezer at $-80{ }^{\circ} \mathrm{C}$ to prevent degradation of the bioactive compounds. Total phenolic concentration (TPC) and phenolics composition, ascorbate (ASC), pigments (carotenoids and 
chlorophylls) concentrations and antioxidant activity (AA) in lyophilised fruit samples were measured.

Seeds from 10 randomly selected fruit of each male-female combination were extracted and dried, then stored in a dry place until analysis. The seeds protein spectrum was determined.

Chemicals, reagents and apparatus

All reagents and phenolic standards used for highperformance liquid chromatography (HPLC) were of HPLC grade and purchased from Sigma-Aldrich (Poznań, Poland) and Fluka (Bucharest, Romania). Other chemicals were of analytical purity and purchased from Alchem (Warsaw, Poland). The HPLC set-up used in the study consisted of two LC-20AD pumps, a CMB-20A system controller, a SIL-20AC autosampler, an ultraviolet-visible SPD-20AV detector, a CTD-20AC oven and a Fusion-RP 80A column, $250 \times 4.60 \mathrm{~mm}$ (for phenolics) or Max-RP 80A column, $250 \times 4.60 \mathrm{~mm}$ (for carotenoids and chlorophylls), and Luna $5 \mu \mathrm{m} \mathrm{C} 18,150 \times 4.60 \mathrm{~mm}$ (for ascorbate), all Shimadzu products (Polish agent Shimpol, Warsaw, Poland). For AA and TPC determination, spectrophotometers UV/Vis UV-6100A, (Metash Instruments Co., Ltd, Shanghai, P. R. China) and Thermo Scientific Helios $\gamma$ (Fisher Scientific, USA), respectively were used.

\section{Determination of phenolics and ascorbate (ASC)}

The total phenolics (TPC) content was determined by the Folin-Ciocalteu method based on the method modified by Singleton et al. (1999). The $250 \mathrm{mg}$ of the lyophilized fruit sample was extracted in $25 \mathrm{ml}$ of distilled water in an incubator with a vortex [IKA KS 4000 Control, IKA] for $60 \mathrm{~min}$ at temp. $30{ }^{\circ} \mathrm{C}$ and then, spun in a centrifuge with a cooling system (Centrifuge, MPW-380 R; temp. $5{ }^{\circ} \mathrm{C}, 12076 \times g$, $20 \mathrm{~min}$ ). Phenolics were determined by the reading of absorbance at $750 \mathrm{~nm}$ and the results were expressed as GAE (Gallic Acid Equivalent) per $100 \mathrm{~g}$ of tested material.

Phenolic compounds were separated using HPLC (Hallmann and Rembiałkowska 2012). Fruit samples consisting of $100 \mathrm{mg}$ of lyophilized powder were extracted with $80 \%$ methanol using an ultrasonic bath $\left(10 \mathrm{~min}, 30^{\circ} \mathrm{C}\right)$. Samples were then centrifuged (12 min, $5500 \mathrm{rpm}, 2{ }^{\circ} \mathrm{C}$ ) and next, after dilution,
$1 \mathrm{~mL}$ of the supernatant was transferred into HPLC vials. Samples were separated under gradient conditions with a flow rate of $1 \mathrm{~mL} \mathrm{~min}^{-1}$ by applying an aqueous solution of $10 \%(\mathrm{v} / \mathrm{v})$ acetonitrile (phase A) and $55 \%$ acetonitrile (phase B). The phases changed as follows: $\quad 1.00-22.99 \mathrm{~min}$ phase A $95 \%$, 23.00-27.99 min phase A 50\%, 28.00-28.99 min phase A $80 \%, 29.00-35.99 \mathrm{~min}$ phase A $80 \%$, 36.00-38.00 min phase A 95\%. The wavelength used for detection was $270-360 \mathrm{~nm}$. The concentration of individual phenolic compounds was calculated based on standard curves and samples dilution coefficients.

The total ascorbate concentration (sum of L-ascorbic acid (L-AA) and dehydroascorbic acid (DHAA), reduced and oxidised, respectively) was measured after complete oxidation of L-AA to DHAA with ascorbate oxidase. Dehydroascorbate was derivatised with O-phenylenediamine and the reaction product was detected as a fluorescent compound (350/ $450 \mathrm{~nm}$ ). More details can be found in a previous paper (Latocha et al. 2015).

\section{Determination of pigments}

Carotenoids and chlorophylls were measured by HPLC as described by Hallmann and Rembiałkowska (2012) with some modifications. Sample preparation included extraction of a $100 \mathrm{mg}$ lyophilised sample with $5 \mathrm{~mL}$ of $100 \%$ acetone using an ultrasonic bath $\left(10 \mathrm{~min}, \quad 0^{\circ} \mathrm{C}\right)$. Samples were then centrifuged (10 min, $6000 \mathrm{rpm}, 0^{\circ} \mathrm{C}$ ). A volume of $1 \mathrm{~mL}$ of supernatant was transferred into an HPLC vial. A mixture of methanol + acetonitrile-10/90 (v/v) (phase A) and methanol + ethyl acetate-32/68 (v/ v) (phase B) at a flow rate of $1 \mathrm{~mL} \mathrm{~min}^{-1}$ was used as a gradient solvent (1.00-14.99 min phase A $100 \%$, 15.00-22.99 min phase A 40\%, 24.00-27.00 min phase A 100\%). The wavelength used for detection was $445-450 \mathrm{~nm}$. The concentrations of carotenoids and chlorophylls were calculated using standard curves and the samples dilution coefficients and are presented in mg per $100 \mathrm{~g}$ of lyophilised material.

Antioxidant activity

Antioxidant activity (AA) in water extracts of the tested material was determined using ABTS radical cation assay according to a modified method Re et al. (1999). $100 \mu \mathrm{L}$ of diluted extract was drawn into glass 
test tubes. Afterwards, $3.0 \mathrm{ml}$ of radical cations' ABTS $+\bullet$ in PBS solution was added. The absorbance at the wave length of $\lambda=734 \mathrm{~nm}$ was read exactly after 6 min of incubation at room temperature. The results are expressed as mM TEAC (Trolox Equivalent Antioxidant Capacity) per $100 \mathrm{~g}$ of tested material.

\section{Seed protein analysis}

Seeds from 10 fruit of each male-female combination were extracted, dried and then stored in a dry place until analysis. Singular seeds were crushed and proteins were extracted with $20 \mu \mathrm{L}$ of urea buffer with the following formula: $2.6 \mathrm{M}$ urea solution, $5 \%$ DTT, $0.22 \mathrm{M}$ SDS, and $0.02 \%$ bromophenol blue. Samples were then left overnight at room temperature, boiled for $3 \mathrm{~min}$ and centrifuged at $18000 \times \mathrm{g}$ for $3 \mathrm{~min}$ at $15{ }^{\circ} \mathrm{C}$. Protein samples were loaded onto trisGlycine 4-12\% gradient polyacrylamide gels (Jule, Inc., Milford, CT, USA). The gel size was $140 \times 160 \times 1.5 \mathrm{~mm}$. Proteins were separated by SDS-PAGE electrophoresis in Tris-Glycine running buffer for $4 \mathrm{~h}$ in a current of 50/30 mA per gel. Serva Molecular Weight marker 6.5-200 kDa, liquid mix was used (myosin $200 \mathrm{kDa}, \beta$-galactosidase $116 \mathrm{kDa}$, albumin (bovine) $67 \mathrm{kDa}$, ovalalbumin (egg) $45 \mathrm{kDa}$, carbonic anhydrase $29 \mathrm{kDa}$, trypsin inhibitor (soybean) $21 \mathrm{kDa}$, lysozyme $14.3 \mathrm{kDa}$ and aprotinine $6.5 \mathrm{kDa}$ ). Gels were stained with Coomassie G250 to visualize proteins.

Statistical analysis of the data

All morphological and chemical determinations were made in three replications and are expressed as mean values. To verify the statistical significance, the data were statistically processed by means of two-way factors (male and female parent) analysis of variance (ANOVA) with interaction, using STATISTICA software (TIBCO Software Inc. (2017), http://statistica. io., USA). Because of multiple testing performed in the study the Bonferroni correction was used in order to control family-wise error (FWER) (Dunn 1961). To evaluate the significance of the differences between mean values, Tukey's Honestly Significant Difference (HSD) multiple comparison procedure was applied at a significance level of $P \leq 0.05$.

\section{Results and discussion}

Fruit fresh weight (FW)

Kiwiberry mean fruit weight ranged between $5.2 \mathrm{~g}$ ('Weiki' $\times$ 'Rot', 2015) and $10.0 \mathrm{~g}$ ('Weiki' $\times$ ' Rubi', 2016), on average (Table 1). Irrespective of pollen sources the fruits harvested in 2015 were of similar weight. Somewhat greater differences in fruit weight were obtained in the next growing season (2016). 'Geneva' fruit pollinated by A. chinensis var. deliciosa 'Tomuri' was characterized by a significantly lower fruit weight (5.7 g) compared to 'Weiki' fruit pollinated with 'Rubi' pollen $(10.0 \mathrm{~g})$. Fruits of all other treatments did not differ significantly. Except for 'Geneva' $\times$ 'Tomuri', fruits derived from all other combinations were bigger in 2016 than in 2015. The biggest difference in fruit weight between the two analyzed growing seasons occurred for 'Bingo' $x$ ' Nostino' (ca. 67\%). This was probably due to the differences in the amount of precipitation between both years (dry 2015 vs. wet 2016-Supplementary material 1). Based on those results (Table 1), it can be concluded that the genetically different pollen sources affected the weight of the kiwiberry fruit to only a small degree regardless of the male or female cultivar used. In research made by Seal et al. (2018) on kiwifruit, the different pollen source influenced the fruit weight but seed number remain unchanged and it was connected with different ploidy level of pollen donors. Usually seed number is positively correlated with fruit weight. In our study, probably the small size of the kiwiberry fruit was the reason that significant differences in fruit weight after pollination with genetically different pollen did not occur. Greater differences in fruit weight were likely caused by weather conditions.

\section{DM, TPC and ASC concentration}

Dry matter (DM) is fast becoming a valuable indicator of quality due to its relationship with postharvest soluble solids content via starch hydrolysis. The biggest advantage of this indicator is its stability from harvest to consumption (Jordon and Seelye 2009). Consumers usually prefer fruits with a higher DM content (Burdon et al. 2004). In our experiment genetically diverse pollen source significantly influenced the DM concentration of kiwiberry fruit 
Table 1 Effect of different pollen sources $(n=5)$ and female cultivar $(n=3)$ on fruit weight $\left(\mathrm{g}\right.$ fruit ${ }^{-1}$ ) depending on growing season. Data are presented as mean $\pm \mathrm{SD}, n=30$

The values marked with different letters (the second column, year 2016) differ significantly at $P \leq 0.05$ according to Tukey HSD test

$N S$ not significant

\begin{tabular}{lll}
\hline Experimental combination (female $\times$ male parent) & \multicolumn{2}{l}{ Average fruit weight $(\mathrm{g})$} \\
\cline { 2 - 3 } & 2015 & 2016 \\
\hline Weiki $\times$ Rubi & $7.0 \pm 1.8$ & $10.0 \pm 1.3 \mathrm{a}$ \\
Bingo $\times$ Nostino & $5.4 \pm 1.4$ & $9.0 \pm 1.4 \mathrm{ab}$ \\
Weiki $\times$ Nostino & $5.7 \pm 0.5$ & $8.9 \pm 1.5 \mathrm{ab}$ \\
Weiki $\times$ Rot & $5.2 \pm 1.5$ & $8.8 \pm 1.0 \mathrm{ab}$ \\
Bingo $\times$ Rubi & $6.5 \pm 0.4$ & $8.7 \pm 0.4 \mathrm{ab}$ \\
Geneva $\times$ Nostino & $6.8 \pm 1.1$ & $8.6 \pm 1.3 \mathrm{ab}$ \\
Geneva $\times$ Rubi & $5.5 \pm 0.9$ & $8.4 \pm 0.1 \mathrm{ab}$ \\
Bingo $\times$ Rot & $6.1 \pm 0.3$ & $8.2 \pm 0.3 \mathrm{ab}$ \\
Geneva $\times$ Rot & $5.7 \pm 0.5$ & $8.1 \pm 1.3 \mathrm{ab}$ \\
Bingo $\times$ Joker & $6.6 \pm 0.8$ & $7.2 \pm 0.8 \mathrm{ab}$ \\
Geneva $\times$ Joker & $6.1 \pm 0.5$ & $7.1 \pm 1.1 \mathrm{ab}$ \\
Bingo $\times$ Tomuri & $6.0 \pm 1.2$ & $6.8 \pm 1.2 \mathrm{ab}$ \\
Weiki $\times$ Tomuri & $6.0 \pm 2.4$ & $6.5 \pm 1.8 \mathrm{ab}$ \\
Weiki $\times$ Joker & $5.5 \pm 2.1$ & $6.3 \pm 1.2 \mathrm{ab}$ \\
Geneva $\times$ Tomuri & $6.4 \pm 1.1$ & $5.7 \pm 0.9 \mathrm{~b}$ \\
Significance male parent $(P$ value $)$ & $\mathrm{NS}$ & 0.036 \\
Significance female parent $(P$ value $)$ & $\mathrm{NS}$ & 0.000 \\
Significance female $\times$ male parent $(P$ value $)$ & $\mathrm{NS}$ & $\mathrm{NS}$ \\
\hline & & \\
\hline
\end{tabular}

(Fig. 1a). The DM content ranged between 19.2 and $23.5 \mathrm{~g}^{100 \mathrm{~g}^{-1}}$ FW for 'Bingo' $\times$ 'Rubi' and 'Bingo' $\times$ 'Rot', respectively. Significantly lower DM was found for the 'Bingo' cultivar pollinated by A. arguta male cultivars 'Joker', 'Nostino' and 'Rubi'. Pollination of this female cultivar by pollen from other species or cultivars resulted in a much higher DM-

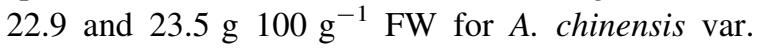
deliciosa 'Tomuri' and A. arguta var. purpurea 'Rot', respectively. Fruit of the 'Weiki' cultivar had the highest DM content when 'Nostino', 'Rubi' or $A$. arguta var. purpurea 'Rot' were used as pollinators. The lowest differences between DM content were noted for 'Geneva' and its pollinizers (Fig. 1a). Similar results were obtained by Seyrek et al. (2017). They found that the DM content of Actinidia eriantha fruit pollinated by male genotype MH67 increased significantly (up to $18.3 \% \mathrm{DM}$ ) in comparison to control pollinations ( $16.8 \% \mathrm{DM})$. This type of pollen action was confirmed by Seal et al. (2013) in a study with $A$. deliciosa and A. chinensis. An explanation of the authors was that reduction in the number of fertilized ovules resulting from partial incompatibility led to a decline the fruit FW and DM contents.
Depending on the pollen source and female cultivars used, the TPC concentration ranged from 111.0 ('Weiki' $\times$ 'Rubi') to 1557.7 ('Geneva' $\times$ 'Joker') mg GAE $100 \mathrm{~g}^{-1} \mathrm{DW}$ and the ASC concentrations from 187.2 ('Weiki' $\times$ 'Tomuri') to 363.8 ('Bingo' $\times$ 'Joker') mg GAE $100 \mathrm{~g}^{-1}$ DW (Fig. 1b). On average, the highest concentration of TPC was measured for 'Geneva' fruit and the lowest for 'Weiki'. The 'Joker' pollen had the most noticeable effect on TPC concentration among the 'Geneva' and 'Bingo' fruits. The lowest TPC for these cultivars was measured when pollen of cultivars 'Rubi' and 'Rot' (for 'Geneva') or 'Nostino, 'Rubi' and A. chinensis var. deliciosa 'Tomuri' (for 'Bingo') was used. For cultivar 'Weiki' significantly higher TPC was measured when pollens of 'Nostino', 'Rot' and A. chinensis var. deliciosa 'Tomuri' were used. Genetically variable pollen sources clearly influenced TPC but have no significant impact on ASC (Fig. 1c). The ASC content varied between 187.2 and $363.8 \mathrm{mg}$ $100 \mathrm{~g}^{-1}$ DW but differences between treatments were not proved statistically. It seems that the content of ASC in A. arguta fruit depends more on environmental factors than on the source of pollen. Genetically different pollen influenced ASC concentration of date 
Fig. 1 Effect of different pollen sources $(n=5)$ and female cultivars $(n=3)$ on fruit quality characters including dry matter (g 100 $\left.\mathrm{g}^{-1} \mathrm{FW}\right)(\mathbf{a})$, total phenolics (mg GAE $100 \mathrm{~g}^{-1}$ DW) (b) and ascorbate contents (mg $100 \mathrm{~g}^{-1} \mathrm{DW}$ ) (c) as well as total antioxidant activity (mM TEAC $100 \mathrm{~g}^{-1}$ DW) (d) of A. arguta female cultivars.

The values represent average of three replication. The values marked with different letters differ significantly at $P \leq 0.05$ according to Tukey HSD test. Anova significance for male parent, female parent and male $\times$ female (graphs $\mathbf{a}, \mathbf{b}$ and $\mathbf{d})$ at $P$ value $<0.001$; for graph c-not significant, NS (male parent and male $\times$ female) and significant at $P$ value $<0.001$ for female parent
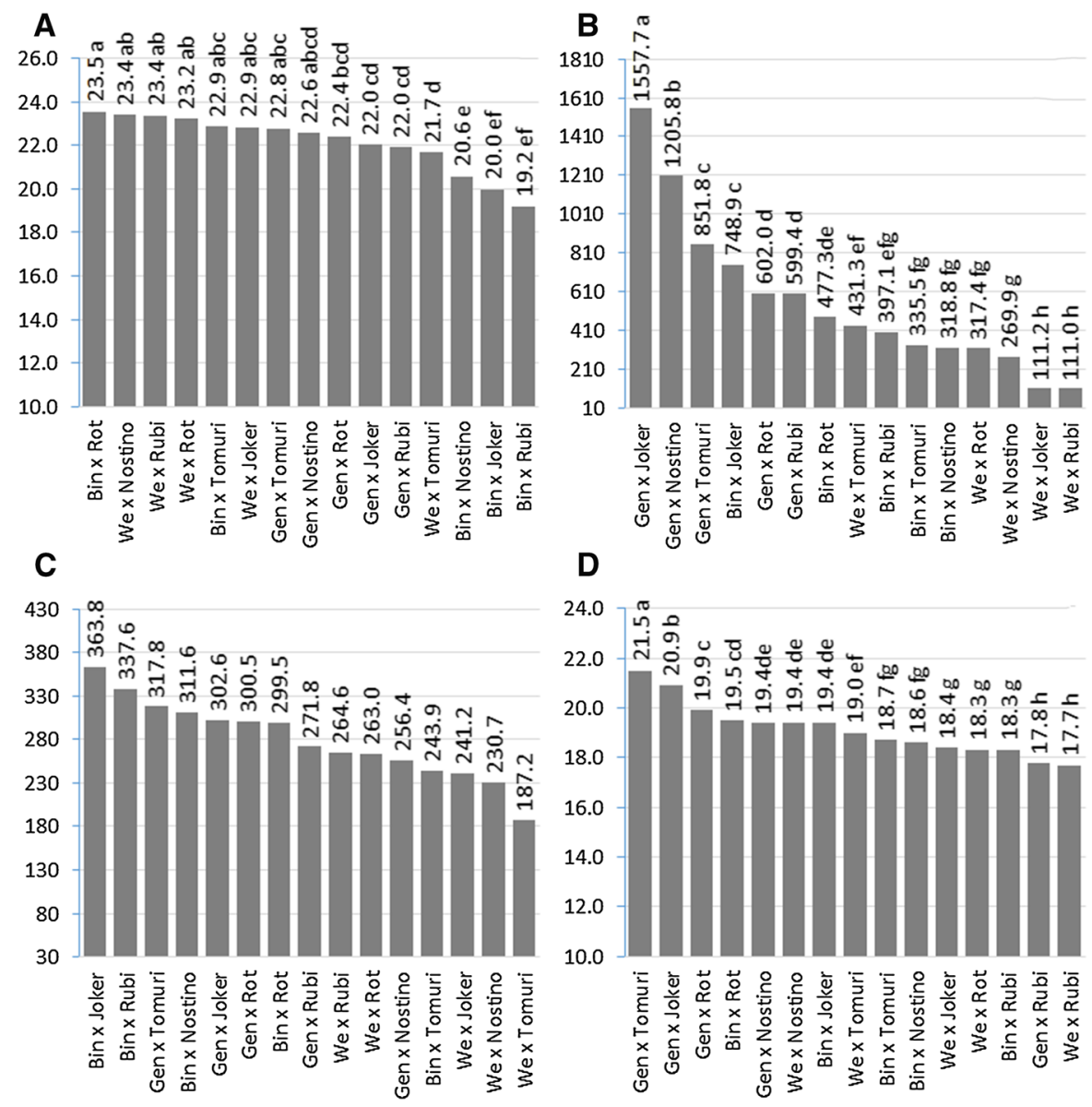

palm (Shafique et al. 2011). However, the authors of that study did not find any effect of pollen source on TPC. In contrast, significant differences in TPC in Actinidia eriantha pollinated with different pollen sources were observed by Seyrek et al. (2017). The authors reported TPC concentrations in A. eriantha in the range $0.26-0.56 \mathrm{mg} \mathrm{g}^{-1} \mathrm{FW}$. The largest increase in concentration of phenolics was found after pollination by A. eriantha genotypes M67 and M45. In our experiment 'Joker' pollen was the best choice in relation to TPC concentration of 'Geneva' and 'Bingo' fruit. In turn, 'Weiki' fruit was richest in TPC when the male parent was A. chinensis var. deliciosa 'Tomuri'.

\section{Antioxidant activity (AA)}

Very large variation in the fruit AA occurred. This was expected because AA in Actinidia ssp. is closely related to the concentration of TPC and ASC (Latocha et al. 2013), which also varied considerably among tested treatments. Significant differences in AA between male and female combinations were found (Fig. 1d). The highest AA measured by ABTS assay was expressed by 'Geneva' fruit pollinated by $A$. chinensis var. deliciosa 'Tomuri' (20.9 mM TEAC $100 \mathrm{~g}^{-1} \mathrm{DW}$ ) while the lowest AA was found when each female cultivar was pollinated by $A$. arguta 'Rubi' (17.8, 17.7 and $18.3 \mathrm{mM}$ TEAC $100 \mathrm{~g}^{-1} \mathrm{DW}$ for 'Geneva', 'Weiki' and 'Bingo', respectively). This may be explained by the different phenolic composition and ASC concentration in fruit of these genotypes. It is commonly known that particular phenolic compounds express different antioxidant potential (RiceEvans et al. 1997). To our knowledge, no research on xenia effects on fruit AA is available currently.

Identification of phenolic compounds (HPLC)

As result of HPLC phenolic separation, four phenolic acids (gallic, chlorogenic, coffeic and p-coumaric 
acids) and five flavonoids (rutinozid-3-O-quercetine, glikozide-3-O-quercetine, glikozide-3-O-kempferol, myrycetin and luteolin) were identified (Fig. 2). Gallic and p-coumaric acids followed by rutinozid-3-0quercetine were established to be the dominant components of phenolic extracts irrespective of pollen source (Fig. 2a, d, e). Myrycetin and luteolin were the flavonoids with the lowest concentration in all tested fruits (Fig. 2h, i). Although the impact of a pollinizer on the concentration of individual compounds was statistically proven, a clear relationship to the pollen source could not be established. Pollinizer effects were found to depend strongly on each examined phenolic compound. In general, the male genotypes 'Joker' and 'Nostino' were the best sources, with respect to the fruit phenolic contents of 'Geneva'. With regard to 'Bingo and 'Weiki', the pollen effect patterns on phenolics were highly variable. One notable observation was the fairly negative relationship between pollen of A. arguta var. purpurea 'Rot' and A. chinensis var. deliciosa 'Tomuri' and most phenolic compound contents (Fig. 2). In conclusion, genetically diverse pollen can modify the quali-quantitative distribution patterns of kiwiberry fruit phenolics. However, further research is needed to outline the mechanism of pollen action. Among the examined female cultivars, 'Geneva' was characterized by the fruit richest in all compounds with the exception of myrycetin and luteolin (Fig. 2). Similar tendency for kiwifruit were observed by Seal et al. (2016, 2018). The authors found significant differences depended on pollen donors in anthocyanin concentration in kiwifruit which resulted in intensity of pericarp red colour variation. This variation was partially explained by different ploidy level of male parents. To our knowledge, there are no published data concerning xenia effect on kiwiberry (A. arguta) fruit phenolic concentration.

\section{Carotenoids and chlorophylls}

The influence of pollen sources on the fruit's pigment composition was also statistically proven (Fig. 3). Fruits of 'Geneva' and 'Weiki' pollinated with $A$. chinensis var. deliciosa 'Tomuri' or A. arguta 'Joker' pollen were found to have the highest concentration of total pigments with 'Bingo' having the lowest (Fig. 3h). Pollination by 'Nostino' and 'Rubi' resulted in 'Weiki' having the lowest chlorophyll concentration
(11.6 mg $100 \mathrm{~g}^{-1}$ DW and $11.4 \mathrm{mg} 100 \mathrm{~g}^{-1} \mathrm{DW}$ respectively) (Fig. 3g). The lowest chlorophyll concentration in 'Geneva' fruit were noted when 'Nostino' and 'Rot' as pollinizers were used.

Differences in fruit pigments concentration between female cultivars were also observed. The highest amounts of carotenoids and chlorophylls (with the exception of lutein) was found for 'Weiki'. The fruit of 'Geneva' cultivar was characterised by the highest amount of lutein (1.3-1.8 mg $\left.100 \mathrm{~g}^{-1} \mathrm{DW}\right)$ (Fig. 3b).

There is very little information about effect of different pollen sources on carotenoids and chlorophylls concentrations in fruits or vegetables. Variation in carotenoids and chlorophyll concentration in Actinidia eriantha pollinated with various pollens was observed by Seyrek et al. (2017). They investigated the effects of four different pollen sources on selected traits of A. eriantha fruit. In their study, carotenoid concentrations in fruit ranged from 0.95 to $2.00 \mathrm{mg}$, and chlorophyll $a$ concentrations from 2.2 to $4.4 \mathrm{mg}$ $100 \mathrm{~g}^{-1} \mathrm{FW}$. The largest increase in the concentration of these compounds was observed after pollination by the genotype M67.

Influence of different pollen sources on the protein composition of seeds

The seed protein pattern is recognized as the most suitable approach for distinguishing and identifying crop cultivars (Cooke 1989; Konarev et al. 2001). In the case of kiwifruit and other Actinidia species, protein patterns consist of low and middle molecular peptides units in the range of 14-45 kDa (Miraghaee et al. 2011; Maddumage et al. 2013; Drzewiecki et al. 2016). Our previous study revealed that it is difficult to distinguish $A$. arguta cultivars on the basis of seed protein pattern (Drzewiecki et al. 2016).

It is known that polyacrylamide gradient gels (due to a decrease of the diffusion effects on band broadening) yield very high resolution protein subunits over a wide range of molecular weights (Hames 1998). It was therefore decided that gradient gel electrophoresis could be especially suitable for our analysis.

The investigated SDS-PAGE electrophoregram of proteins extracted from singular seeds of kiwiberry females crossed with males of different origin is presented in Fig. 2. The proteins extracted from seeds 


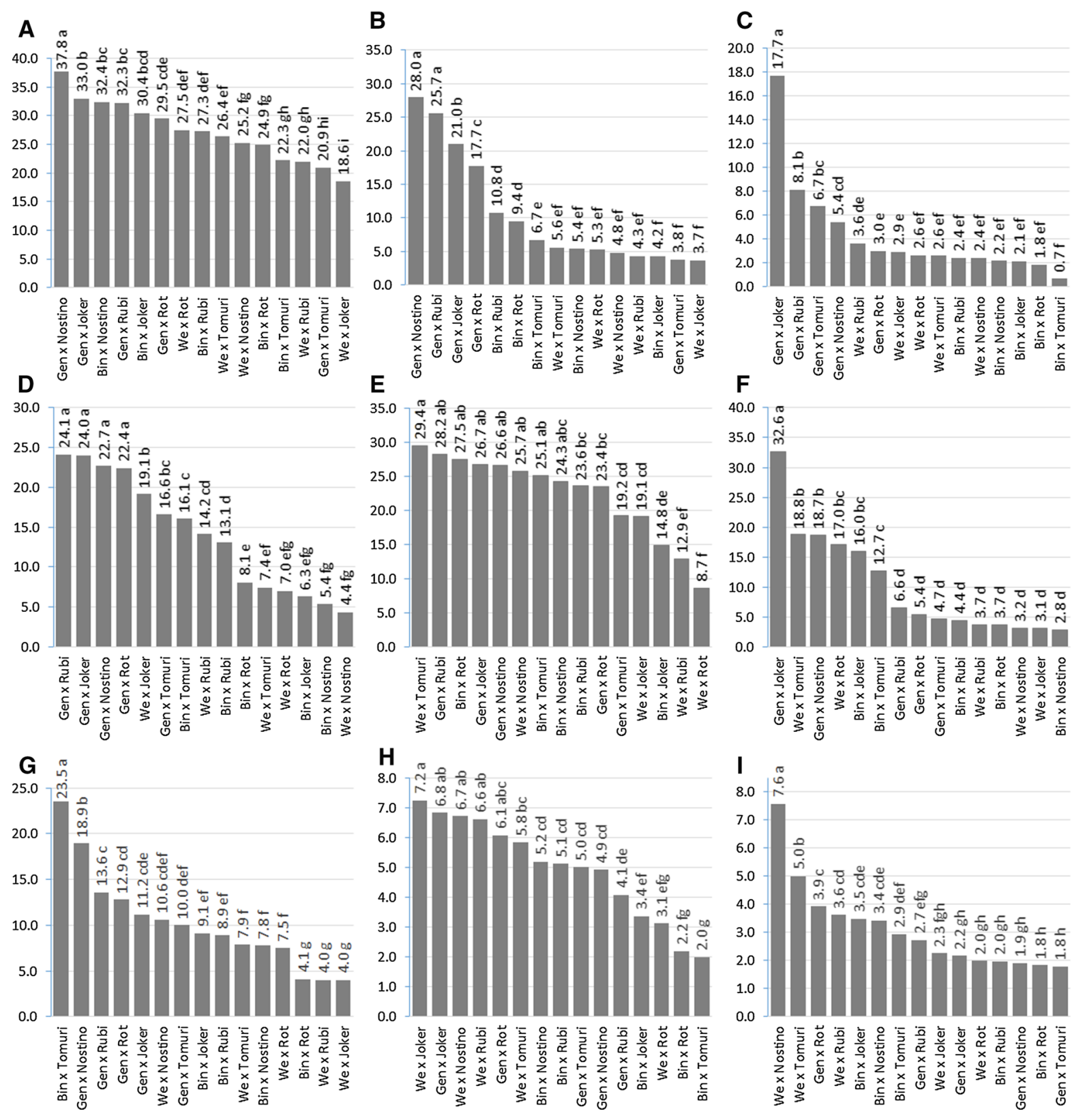

Fig. 2 Fruit phenolic composition depending on cultivar of $A$. arguta and the pollen origin $\left(\mathrm{mg} 100 \mathrm{~g}^{-1} \mathrm{DW}\right)$. Values are mean from three replication. The values marked with different letter differ significantly at $P \leq 0.05$ according to Tukey HSD test. The Anova significance (male parent, female parent and

of each female were quite similar with the exception of 'Geneva'. Our data shows that a $4-12 \%$ gradient gel can reveal seed protein patterns with very high resolution (distinct) bands. We have detected many low molecular peptide units of seeds proteins in the male $\times$ female) for all compounds at $P$ value $<0.001$. Signs: a gallic acid; b chlorogeic acid; $\mathbf{c}$ coffeic acid; $\mathbf{d}$ Rutinozid-3-Oquercetine; e P-coumaric acid; f Glikozide-3-O-quercetine; g Glikozide-3-O-kempferol; h myrycetin; i luteolin

range of 6-22 $\mathrm{kDa}$. This feature helped us to distinguish the 'Geneva' cultivar from 'Bingo' and 'Weiki' - a pair of otherwise indistinguishable cultivars. Earlier, we reported that these cultivars were 

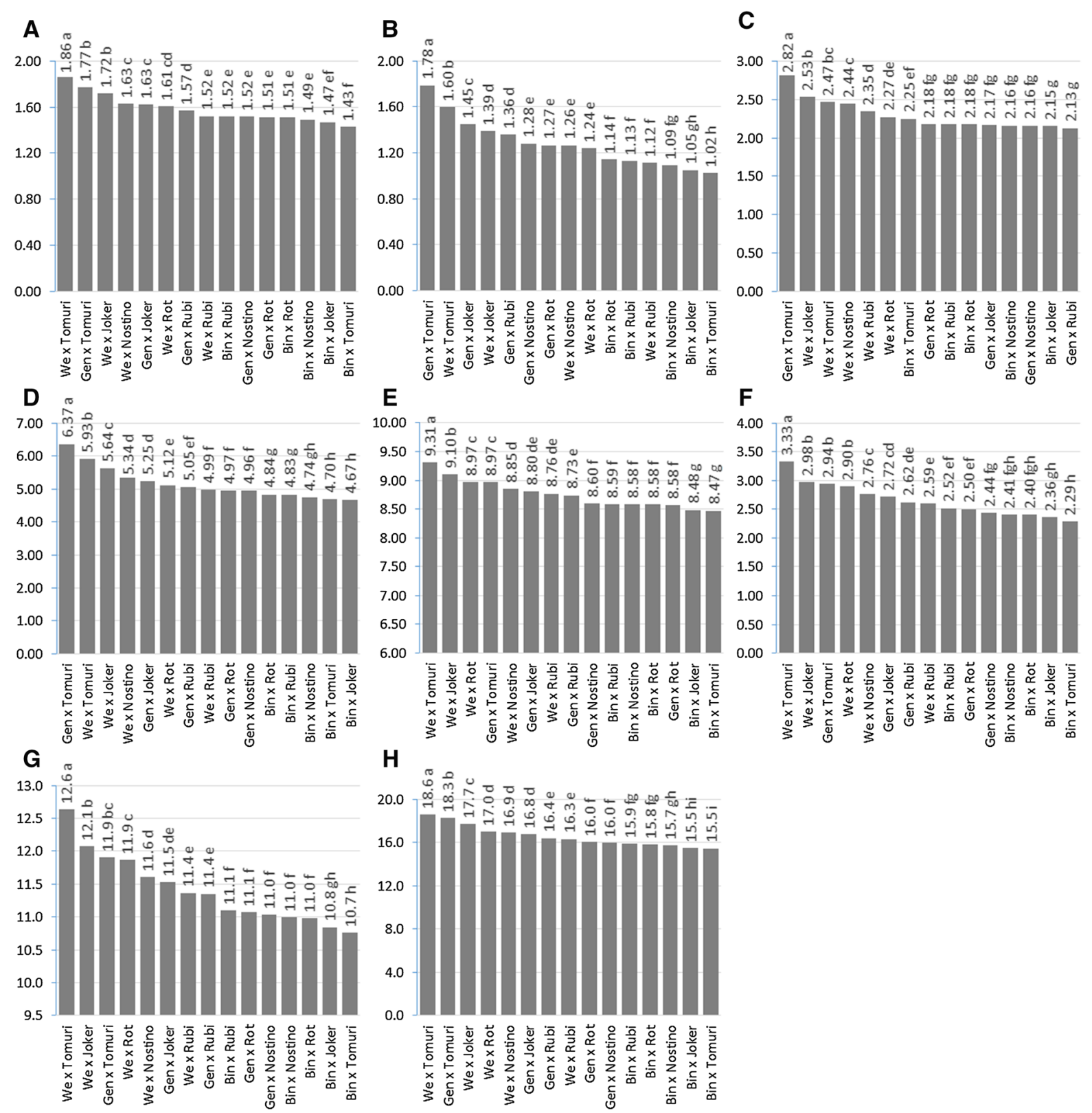

Fig. 3 Fruit pigments (carotenoids and chlorophylls) compositions depending on cultivar of A. arguta and the pollen origin (mg $\left.100 \mathrm{~g}^{-1} \mathrm{DW}\right)$. Values are mean from three replication. The values marked with different letter differ significantly at $P \leq 0.05$ according to Tukey HSD test. Signs: a beta-carotene;

indistinguishable on the basis of seed pattern (Drzewiecki et al. 2016).

The SDS-PAGE spectrum of seed proteins consisted of $6-35 \mathrm{kDa}$ range bands and the number of bands varied from 21 ('Weiki' and 'Bingo') to 23 ('Geneva'). The 'Geneva' female was distinctively b lutein; c zeaxantin; d sum of carotenoids; e chlorophyll $a$; f chlorophyll $b$; $\mathbf{g}$ sum of chlorophylls; $\mathbf{h}$ sum of pigments. The Anova significance (male parent, female parent and male $\times$ female) for all compounds at $P$ value $<0.001$

different from the 'Weiki' and 'Bingo' females due to the presence of two bands (Fig. 4, arrows d and e; band $\mathrm{d}-16.5 \mathrm{kDa}$ - is a major band, characteristic for this female cultivar).

We have not revealed any new bands in genotypes obtained by crossing A. arguta females 'Bingo', 
'Weiki' and 'Geneva' with $A$. arguta males 'Rubi', 'Nostino' and 'Joker'. This finding can be explained by the high biochemical similarity between A. arguta genotypes used for crossing (Drzewiecki et al. 2016). On the other hand, when A. arguta females were crossed with 'Rot' and 'Tomuri' males we could reveal up to three new bands in the protein spectrum. Notably, two bands originated from A. chinensis var. deliciosa 'Tomuri' (Fig. 4, arrows show very distinct $23 \mathrm{kDa}$ bands - arrows a and $17 \mathrm{kDa}$ - arrows $\mathrm{b}$ and one from A. arguta var. purpurea 'Rot' arrow c indicates $16 \mathrm{kDa}$ band). We assume that the newly appearing, distinct bands in crosses between $A$. arguta and $A$. chinensis var. deliciosa may be explained by the higher genetic distance between these species. These bands can be considered as marker bands for the cross-pollination process between these genotypes. Our results therefore support previous data obtained by other scientists. For example, the hybrid character of seeds can be recognized by the phenotypic features
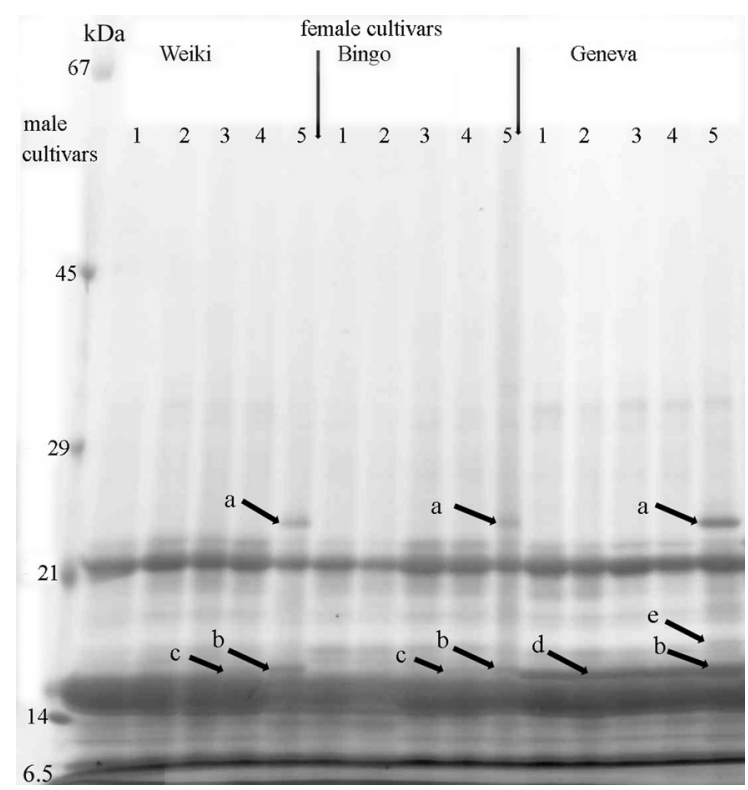

Fig. 4 SDS-PAGE electrophoresis of seed proteins of crosses female $A$. arguta cultivars with five male parents. Female parents: 'Weiki', 'Bingo', 'Geneva'; Male parents: 1-'Rubi' (A. arguta), 2-'Nostino' (A. arguta), 3-'Joker' (A. arguta), 4-'Rot' (A. arguta var. purpurea), 5-'Tomuri' (A. chinensis var. deliciosa). Markers of crossing pollination; a-23 kDa and $\mathrm{b}-17 \mathrm{kDa}$, both derived from A. chinensis var. deliciosa and c- $16 \mathrm{kDa}$-originated from A. arguta var. purpurea. Bands that differ 'Geneva' from 'Weiki' and 'Bingo' cultivars: $d-$ $16.5 \mathrm{kDa}$-major identity band of 'Geneva'; e-18 kDaminor identity band of 'Geneva' of seeds (xenia phenomenon) e.g. in the case of rye where the colour of hybrid seeds may result from the influence of the pollinizer genotype on the embryo (Grochowski 2003). Regardless of the assessment method, a greater genetic distance between of the parental components favours detecting crossing effect was found. It was confirmed in the example of $A$. arguta interbreeding with $A$. chinensis var. deliciosa and $A$. arguta var. purpurea pollinizers by the presence of marker bands derived from these forms on the seed protein electrophoregram. A dendrogram generated by UPGMA clustering analysis revealed that $A$. arguta and A. chinensis var. deliciosa accessions were grouped into distant clusters created on the basis of isozyme patterns (Testolin and Fergusson 1997), chloroplast and mitochondrial DNA sequences (Chat et al. 2004; Yao and Huang 2016), or RAPD markers of leaves (Huang et al. 2002). In our study, the male effects on seed protein composition could be ascribed to both the ploidy and species differences between female (A. arguta) and male (A. chinensis var. deliciosa) parents (tetraploid vs. hexaploid, respectively). In the case of A. arguta and A. arguta var. purpurea, both taxa were grouped into one minor cluster on the base of mitochondrial DNA sequences (Yao and Huang 2016), which suggests close genetic similarity between these two forms. Molecular and protein features confirm taxonomic opinion that $A$. arguta and $A$. arguta var. purpurea are closely related genotypes, and are therefore classified as A. arguta species. We have not observed marker bands of crosspollination in the case of males of A. arguta; these lines are genetically related to the females examined, and even using high resolution gels we could not reveal male-derived bands in protein patterns. In our opinion seed protein composition could be a valuable indicator of genetically distant pollen sources.

\section{Conclusions}

In summary, the fruit chemical composition of selected female kiwiberry cultivars depended considerably on pollen sources. The biggest pollen effect was found for DM content and phenolic concentrations. The extent of these effects depended on the male and female parents used in the pollination process. Based on the results, we conclude that pollen sources (male vines) should be selected for particular female 
cultivars in order to achieve better fruit biochemical characteristics, especially with respect to phenolic concentrations. Therefore, for female 'Geneva' and 'Bingo' the highest phenolic content was noted when pollen of 'Joker' was used while for female 'Weiki' 'Tomuri' one. No differences in ascorbate concentration as a result of different pollen sources were found. As the concentration of bioactive compounds was found to be strongly dependent on environmental factors, further research in different environmental locations, settings and conditions is needed to confirm our findings.

Clear differences between chemical composition of female parents were found. 'Geneva' showed the highest concentration of the most bioactive compounds tested as well as the total antioxidant activity. Both, the pollen source and female parents were shown to have an impact on the protein composition of A. arguta seeds. The protein profiles of seeds pollinated with $A$. chinensis var. deliciosa pollen differed markedly from those of seeds pollinated with A. arguta pollen. Similarly, the protein profile of 'Geneva' seeds differed from those of the other female cultivars tested. Our findings suggest that both, $A$. chinensis var. deliciosa 'Tomuri' (hexaploid) and four tested $A$. arguta (tetraploids) male genotypes may be suitable pollinizers for kiwiberry production. Further work is needed to separate the effects of ploidy differences from the effects of other genetic differences between seed and pollen parents. Moreover, the physiological and molecular phenomenon involved in the differential response of different pollen sources also needs further study.

Acknowledgements This research was supported by NCBR Grant No PBS3/A8/35/2015.

Open Access This article is distributed under the terms of the Creative Commons Attribution 4.0 International License (http:// creativecommons.org/licenses/by/4.0/), which permits unrestricted use, distribution, and reproduction in any medium, provided you give appropriate credit to the original author(s) and the source, provide a link to the Creative Commons license, and indicate if changes were made.

Author contributions AS performed the experiments, as well as wrote the draft of the paper; JD, EH, KN, HL, ML, BE, carried out analytical tests and commented the data; PL was the supervisor who contributed analysis tools and corrected the manuscript.

\section{References}

Ansari M, Davarynejad GH, Tornyai J, Nyéki J, Szabó Z, Soltész M (2010) Effects of self and cross pollination on fruit set and fruit quality of sour cherry cultivars. Int J Hortic Sci $16: 31-36$

Burdon J, McLeod D, Lallu N, Gamble J, Petley M, Gunson A (2004) Consumer evaluation of "Hayward" kiwifruit of different at-harvest dry matter contents. Postharvest Biol Technol 34:245-255

Chat J, Jáuregui B, Petit RJ, Nadot S (2004) Reticulate evolution in kiwifruit (Actinidia, Actinidiaceae) identified by comparing their maternal and paternal phylogenies. Am J Bot 91:736-747

Cooke R (1989) Electrophoresis in plant testing and breeding. Electrophoresis 2:171-261

Denney JO (1992) Xenia includes metaxenia. HortScience 27:722-728

Drzewiecki J, Latocha P, Leontowicz H, Leontowicz M, Park YS, Najman K, Weisz M, Ezra A, Gorinstein S (2016) Analytical methods applied to characterization of Actinidia arguta, Actinidia deliciosa, and Actinidia eriantha kiwi fruit cultivars. Food Anal Methods 5:1353-1366

Dunn OJ (1961) Multiple comparisons among means. J Am Stat Assoc 56(293):52-64

Ehlenfeldt MK (2003) Investigation of metaxenia in northern highbush blueberry (Vaccinium corymbosum L.) cultivars. J Am Pomol Soc 57:26-31

Fattahi R, Mohammadzedeh M, Khadivi-Khub A (2014) Influence of different pollen sources on nut and kernel characteristics of hazelnut. Sci Hortic 173:15-19

Ferreira JJ, Alvarez E, Fueyo MA, Roca A, Giraldez R (2000) Determination of the outcrossing rate of Phaseolus vulgaris L. using seed protein markers. Euphytica 3:257-261

Grochowski L (2003) Xenia in rye, its types and significance for breeding of hybrid cultivars. Biul IHAR 230:215-233 (in Polish)

Grochowski L, Kaczmarek J, Kadłubiec W, Bujak H (1995) Using xenia in the breeding of rye hybrids. Acta Soc Bot Pol 64:175-179

Hallmann E, Rembiałkowska E (2012) Characterisation of antioxidant compounds in sweet bell pepper (Capsicum annиит L.) under organic and conventional growing systems. J Sci Food Agric 92:2409-2415

Hames BD (1998) Gel electrophoresis of proteins. A practical Approach, 3rd edn. Oxford University Press, Oxford

Hom NH (2004) Pollen genotype effects on seed quality and selection of single seeds by near-infrared reflectance spectroscopy (NIRS) in winter oilseed rape. Dissertation, Georg-August University of Göttingen, Germany

Huang H (2014) The genus Actinidia a world monograph. Science Press, Beijing

Huang H, Li Z, Li J, Kubisiak TL, Layne DR (2002) Phylogenetic relationships in Actinidia as revealed by RAPD analysis. J Am Soc Hortic Sci 127:759-766

Jordon RB, Seelye RJ (2009) Relationship between taste perception, density and soluble solids concentration in kiwifruit (Actinidia deliciosa). N Z J Crop Hortic Sci 37:303-317 
Komosa A (2012) Żywienie roślin ogrodniczych podstawy i perspektywy. Powszechne Wydawnictwo Rolnicze i Leśne, Poznań, pp 349-357 (in Polish)

Konarev VG, Gavriljuk IP, Gubareva NK (2001) Morphogenesis and molecular-biological analysis of plants, 2nd edn. suppl. SPb, V I R

Latocha P (2017) The nutritional and health benefits of kiwiberry (Actinidia arguta) — a review. Plant Foods Hum Nutr 72:325-334

Latocha P, Wołosiak R, Worobiej E, Krupa T (2013) Clonal differences in antioxidant activity and bioactive constituents of hardy kiwifruit (Actinidia arguta) and its yearto-year variability. J Sci Food Agric 93:1412-1419

Latocha P, Łata B, Stasiak (2015) Phenolics, ascorbate and the antioxidant potential of kiwiberry vs. common kiwifruit: the effect of cultivar and tissue type. J Funct Foods 19:155-163

Leontowicz H, Leontowicz M, Latocha P, Jesion I, Park Y-S, Katriche E, Barasche D, Nemirovski A, Gorinstein S (2016a) Bioactivity and nutritional properties of hardy kiwi fruit Actinidia arguta in comparison with Actinidia deliciosa 'Hayward' and Actinidia eriantha 'Bidan'. Food Chem 196:281-291

Leontowicz M, Leontowicz H, Jesion I, Bielecki W, Najman K, Latocha P, Park Y-S, Gorinstein S (2016b) Actinidia arguta supplementation protects aorta and liver in rats with induced hypercholesterolemia. Nutr Res 36:1231-1242

Maddumage R, Nieuwenhuizen NR, Bulley SM, Cooney JM, Green SA, Atkinson RG (2013) Diversity and relative levels of Actnidin, Kiwellin and Thaumatin-like allergens in 15 varieties of kiwifruit (Actinidia). J Agric Food Chem 61:728-739

Militaru M, Butac M, Sumedrea D, Chitu E (2015) Effect of metaxenia on the fruit quality of scab resistant apple varieties. Agric Agric Sci Procedia 6:151-156

Miraghaee SS, Mostafaie A, Kiani S, Kahrizi D (2011) Investigation on protein pattern in kiwifruit (Actinidia deliciosa). World Appl Sci 15:1398-1402

Olfati JA, Sheykhtaher Z, Qamgosar R, Khasmakhi-Sabet A, Peyvast Gh, Samizadeh H, Rabiee B (2010) Xenia and metaxenia on cucumber fruit and seed characteristics. Int $\mathbf{J}$ Veg Sci 16:243-252

Piotto FA, Batagin-PiottoII DK, de AlmeidaII M, Oliveira GCX (2013) Interspecific xenia and metaxenia in seeds and fruits of tomato. Sci Agric 70:102-107

Pourghayoumi M, Bakhshi D, Rahemi M, Jafari M (2012) Effect of pollen source on quantitative and qualitative characteristics of dried figs (Ficus carica L.) cvs 'Payves' and 'Sabz' in Kazerun-Iran. Sci Hortic 147:98-104

Qiu Y-P, Dai H-F, Li Z-Q, Ou L-I, Xiang X, Chen J-Z, Wang B-X (2006) Effects of pollinator on fruit quality of Guiwei litchi cultivar. J Fruit Sci 23:703-706

Qj X-J, Han L-X, Li M, Xu S-K, Zhu Y-S, Li W-X, Qiao S-R (2007) Studies on pollen xenia of kiwifruit. J Fruit Sci 24:774-777

Re R, Pellegrini N, Proteggente A, Nala A, Yang M, Rice-Evans C (1999) Antioxidant activity applying an improved ABTS radical cation decolorization assay. Free Radical Biol Med 26(9/10):1231-1237

Rice-Evans C, Miller NJ, Paganga G (1997) Antioxidant properties of phenolic compounds. Trends Plant Sci 2(4):152-159

Sabir A (2015) Xenia and metaxenia in grapes: differences in berry and seed characteristics of maternal grape cv. 'Narince' (Vitis vinifera L.) as influenced by different pollen sources. Plant Biol 17:567-573

Seal AG, Dunn JK, De Silva HN, McGhie TK, Lunken RCM (2013) Choice of pollen parent affects red flesh colour in seedlings of diploid Actinidia chinensis (kiwifruit). N Z J Crop Hortic Sci 41:207-218

Seal AG, McGhie TK, Boldingh H, Rees J, Blackmore A, Jaksons P, Machin T (2016) The effect of pollen donor on fruit weight, seed weight and red colour development in Actinidia chinensis 'Hort22D'. N Z J Crop Hortic Sci 44(1):1-12

Seal AG, Blackmore A, Jaksons P, McAtee P, Chenget CH (2018) Pollen donor effects on the expression of red flesh colour in kiwifruit. Acta Hortic 1218:373-380

Seyrek UA, Luo M, Zhong M, Huang Ch, Tao J, Qu X, Xu X (2017) Effects of stored pollens from wild Actinidia eriantha vines on some fruit quality traits. Agric Sci 8:465-478

Shafique M, Khan AS, Malik AU, Shahid M, Rajwana IA, Saleem BA, Amin M, Ahmad I (2011) Influence of pollen source and pollination frequency on fruit drop, yield and quality of date palm (Phoenix dactylifera L.) Cv. Dhakki. Pak J Bot 43:831-839

Shemer A, Biton I, Many Y, Vaknin Y, Lavee S, Avidan B, BenAri G (2014) The olive cultivar 'Picual' is an optimal pollen donor for 'Barnea'. Sci Hortic 172:278-284

Singleton VL, Orthofer R, Lamuela-Raventos RM (1999) Analysis of total phenols and other oxidation substrates and antioxidants by means of Folin-Ciocalteu reagent. Methods Enzymol 299:152-178

Stasiak A, Stefaniak J, Łata B, Latocha P (2017) Efficiency of A. arguta (Siebold et Zucc.) Planch. ex. Miq. pollination using A. deliciosa pollen. J Int Sci Publ Agric Food 5:178-187

Strik B (2005) Growing kiwifruit. PNW 507 Oregon State Univ. Extension Service https://catalog.extension.oregonstate. edu/pnw507. Accessed 20 Mar 2018

Testolin R, Fergusson AR (1997) Isozyme polymorphism in the genus Actinidia and the origin of the kiwifruit genome. Syst Bot 22:685-700

Yao X, Huang H (2016) Cytoplasmic DNA in Actinidia. In: Testolin R, Huang H, Fergusson AR (eds) The kiwifruit genome. Springer, Basel, pp 43-54

Publisher's Note Springer Nature remains neutral with regard to jurisdictional claims in published maps and institutional affiliations. 